\title{
Anti-Muslim Attitudes in The Netherlands: Tests of Contradictory Hypotheses Derived from Ethnic Competition Theory and Intergroup Contact Theory
}

\author{
Michael Savelkoul, Peer Scheepers, Jochem Tolsma and \\ Louk Hagendoorn
}

In this study, we set out to explain anti-Muslim attitudes in the Netherlands. Although the presence and immigration of Muslims have become widely discussed, there is little systematic evidence about the determinants underlying anti-Muslim attitudes. Using data from the Social and Cultural Developments in the Netherlands (SOCON) survey (2005, 2006), containing a more detailed measurement of anti-Muslim attitudes, we tested two contradictory mechanisms, derived from ethnic competition theory and intergroup contact theory. Results from hierarchical structural equation modelling indicate that the relative outgroup size induces both intergroup friendship contact as well as perceptions of ethnic threat. However, only the latter turned out to affect anti-Muslim attitudes directly.

Moreover, our findings revealed that contact with colleagues belonging to ethnic minority groups reduces negative attitudes towards Muslims and mediates the effect of individuallevel determinants on anti-Muslim attitudes. The complementary nature of both ethnic competition theory and intergroup contact theory is illustrated by negative correlation between both mediating mechanisms, as well as the support for a curvilinear relationship between outgroup size and perceived ethnic threat.

\section{Introduction}

During the past decades, social scientists devoted considerable attention to attitudes towards ethnic minorities, refugees or immigrants in general (Scheepers, Gijsberts and Coenders, 2002; McLaren and Johnson, 2007; Schneider, 2008). However, since migration processes have resulted in a relatively large part of the European immigrant population being Muslim, it is rather remarkable that only a few studies have been conducted regarding attitudes towards Muslims in European countries (Sniderman and Hagendoorn, 2007; Strabac and Listhaug, 2008). ${ }^{1}$ This is even more notable given the fact that in recent years, Islam in general, and the presence and immigration of the Muslim population in particular, have become widely discussed throughout the public and political arenas as a result of several events like the terrorist attacks in the USA, Madrid, and London. In 2004, the Netherlands became startled by the murder 
of the Dutch filmmaker Theo van Gogh by a Muslim 'extremist', which resulted in several (attempts of) arson attacks on Islamic elementary schools and mosques.

The relatively small number of existing studies on attitudes towards Muslims can be divided into two groups. The first line of research focuses on describing the consequences of stereo-typing of Muslims (Allen and Nielsen, 2002; Sander, 2006; ECRI, 2008). However, these studies provide no systematic evidence regarding the determinants underlying negative attitudes towards Muslims. The second line of research aims at explaining anti-Muslim attitudes, though the number of these studies is very limited due to the lack of micro-level data (Fetzer and Soper, 2003; Strabac and Listhaug, 2008). Moreover, these studies (Sniderman, Hagendoorn and Prior, 2003, 2004; Sniderman and Hagendoorn, 2007; Strabac and Listhaug, 2008) have been highly time specific, using data from surveys preceding the 11 September 2001 attacks in the USA. Furthermore, previous studies only used a rather limited number of individual- and contextual-level determinants to explain anti-Muslim attitudes (Sniderman et al., 2003, 2004; González et al., 2008; Strabac and Listhaug, 2008).

Current research on anti-Muslim attitudes mainly lacks a systematic and methodologically adequate analysis of the mechanisms previously found to be underlying negative attitudes towards ethnic minorities in general. Here, two main theoretical and moreover contradictory traditions can be distinguished. One tradition builds on propositions derived from realistic group conflict theory and ethnic competition theory, starting from the actual competition between majority and minority groups that is proposed to induce negative attitudes and hostility (Coser, 1956; LeVine and Campbell, 1972; Scheepers, Gijsberts and Coenders, 2002). The other tradition is grounded on intergroup contact theory, starting from actual intergroup contact that is proposed to reduce negative attitudes and hostility (Allport, 1954; Pettigrew and Tropp, 2006). Recently, González et al. (2008) addressed both mechanisms in relation to anti-Muslim attitudes, however, only in a sample of students from six secondary schools. Therefore, the external validity of their findings is limited. Moreover, explanations at the contextual level found in previous studies and referring to actual competition were not yet included.

In our study, we aim to disentangle the determinants of anti-Muslims attitudes more profoundly, taking both theoretical traditions into account. In particular, we will focus on the effect of the relative outgroup size on anti-Muslim attitudes, using rather unique data on the percentage Muslims in geographical regions in the Netherlands. Moreover, we will use more recent data from the 'Social and Cultural Developments in the Netherlands' survey (SOCON 2005, 2006), representative of the national population, as well as a more detailed measurement of anti-Muslim attitudes, compared with previous studies (Strabac and Listhaug, 2008), to test our hypotheses on anti-Muslim attitudes. These hypotheses will be derived from both intergroup contact theory and ethnic competition theory. We will apply hierarchical structural equation modelling techniques to the relationship between contextual and individual-level data for a methodologically more accurate test of the proposed mediating effects. The research question we set out to answer is: to what extent can anti-Muslim attitudes in the Netherlands (2005-2006) be explained in terms of (i) ethnic competition, and/or (ii) intergroup contact?

\section{General Theoretical Expectations}

Since similar determinants underlying unfavourable attitudes towards ethnic minorities in general are supposed to influence anti-Muslim attitudes (Strabac and Listhaug, 2008), we set out to explore two general theories, which actually lead to contradictory expectations on the effect of relative outgroup size on outgroup derogation: ethnic competition theory and intergroup contact theory. We will test both general theories and apply them to explain anti-Muslim attitudes.

The ethnic competition theoretical framework is based on two influential as well as complementary theories, namely realistic group conflict theory and social identity theory (cf. Scheepers, Gijsberts and Coenders, 2002). Realistic group conflict theory assumes that competition between social groups, such as ethnic groups, over scarce resources and values, induces conflict of interest between those groups and eventually antagonistic inter-group attitudes (Coser, 1956; LeVine and Campbell, 1972; Austin and Worchel, 1979). Blalock (1967) made an analytical distinction between actual and perceived competition and linked the group-level phenomenon of intergroup (actual) competition to unfavourable attitudes at the individual-level. Bobo (1988) added another distinction, namely between perceived competition and perceived threat, showing that the first is a strong predictor of the latter. According to Bobo (1988), perceived threat is the most direct determinant of unfavourable attitudes towards ethnic minorities. 
Social identity theory applies a (social-) psychological perspective to explain negative attitudes towards outgroups (Tajfel and Turner, 1979; Tajfel, 1981, 1982; Turner, 1982; Brown, 2000). One of the central mechanisms is the process of categorization (Tajfel, 1981), which leads to group identification. Social identity theory assumes that individuals have a fundamental need to perceive their own (in-) group as superior to other (out-) groups. In order to achieve such a positive group distinctiveness, individuals will apply favourable characteristics that they perceive among ingroup members to themselves, by means of a mental process which is labelled 'social identification' (Brown, 1995). Moreover, they will perceive mainly negative characteristics among outgroup members and generalize this to the whole outgroup. This process is labelled 'social contra-identification' (Billiet, Eisinga and Scheepers, 1996).

Ethnic competition theory brings both complementary theories together, aiming at integrating ' $[. .$. ] the dispositional notions from social identity theory with the situational notions from realistic group conflict theory into one theoretical framework' (Coenders et al., 2004, p. 16). Ethnic competition theory argues that the processes of social identification and social contra-identification become intensified under conditions of actual intergroup competition and/or perceptions of ethnic threat, which eventually will induce negative attitudes towards outgroups (Scheepers, Gijsberts and Coenders, 2002; Coenders et al., 2004). According to ethnic competition theory, perceived threat operates as a mediating factor between, on the one hand, individual and contextual-level determinants referring to competitive interethnic conditions, and, on the other hand, anti-outgroup attitudes. Recently, the findings of Schlueter, Schmidt and Wagner (2008) remonstrated with panel data from two countries that perceived threat is chronologically and causally antecedent to unfavourable attitudes towards outgroups as ethnic competition theory proposes.

The second theoretical tradition we will use to explain anti-Muslim attitudes in the Netherlands, is intergroup contact theory. Allport (1954) stressed that contact between groups can effectively reduce negative attitudes towards outgroups, if contact takes place under 'optimal' conditions, i.e. equal group status within the situation, common objectives, intergroup cooperation, and the support of authorities, law or custom. These conditions were later extended (see e.g. Amir, 1969, 1976; Amir and Ben-Ari, 1986). Recently, Pettigrew and Tropp (2006) concluded, based on the results of their meta-analytical study of intergroup contact theory, that Allport's conditions are not crucial for intergroup contact to reduce negative attitudes towards outgroups, though contact under these conditions will reduce negative attitudes more strongly.

Based on these conditions, several types of contact can be distinguished. According to Amir (1969), one of these conditions is contact which is intimate rather than casual. McLaren (2003, p. 913) argued that negative attitudes towards outgroups will be reduced, if '[...] a contact situation provides an opportunity to see that beliefs are actually similar' and '[...] the primary type of contact that should provide this opportunity, is intimate contact, such as friendship'. Additionally, Dixon and Rosenbaum (2004) argued that workplace contact may meet fewer of Allport's 'optimal contact conditions' and is therefore to be expected to less strongly reduce negative attitudes towards ethnic minorities.

The causal order between intergroup contact and negative attitudes towards outgroups is not uncontested. Nonetheless, based on their meta-analytical study, Pettigrew and Tropp (2006) concluded that the effect of intergroup contact reducing negative attitudes towards outgroup is the most important. Note that the previously mentioned distinction between different types of contact is a contribution to previous research, as contact with friends will be more strongly affected by selectivity (due to the voluntarily nature of friendship), compared to contact with colleagues.

\section{Synthesis of Contradictory Theoretical Expectations}

Ethnic competition theory assumes conditions of actual intergroup competition to induce perceptions of threat and eventually negative attitudes towards outgroups. These competitive conditions can take place at the individual as well as contextual level (Olzak, 1992; Quillian, 1995; Scheepers et al., 2002; Schneider, 2008). Ethnic competition theory has been mainly applied in cross-national contexts, though may also be applied on a regional level within countries. Also within (European) countries considerable regional variance in negative attitudes towards ethnic minorities exists (Wagner et al., 2006; Schlueter and Wagner, 2008; Tolsma, Lubbers and Coenders, 2008; Tolsma, Van der Meer and Gesthuizen, 2009). In our study, we will mainly focus on competitive conditions at the regional level, which are proposed to influence perceived threat and in turn anti-Muslim attitudes. ${ }^{2}$

Previous research used (relative) outgroup size as a proxy for actual competition at the contextual level (Olzak, 1992; Quillian, 1995; Taylor, 1998; Scheepers, 
Gijsberts and Coenders, 2002; McLaren, 2003; Schneider, 2008). In this research, we will focus on the proportion Muslims within geographical regions across the Netherlands. Schneider (2008, p. 54) argued that a larger outgroup might not only increase economic competition, though also ' $[\ldots]$ cultural conflicts over norms and values, identity concerns as well as worries about declining national authority', leading to cultural competition. Therefore, we hypothesize that

H1: (1a) A larger outgroup size in a geographical region will foster people's level of perceived threat in that region, (1b) which in turn will induce people's level of anti-Muslim attitudes.

Intergroup contact theory offers an opposing explanation of the effect of outgroup size on anti-Muslim attitudes. Previous research showed that a larger outgroup proportion increases the likelihood that people will have contact with members of this outgroup (Wagner et al., 2006; Schlueter and Wagner, 2008; Schlueter and Scheepers, 2010). However, intergroup contact is assumed to reduce rather than induce negative attitudes towards outgroups (Allport, 1954). Hence, the effect of relative outgroup size on attitudes towards outgroups is mediated by actual intergroup contact. In our present study, we will distinguish two types of contact, i.e. friends and colleagues, which are both supposed to reduce people's level of anti-Muslim attitudes. ${ }^{3}$ Therefore, we hypothesize that:

H2: A larger outgroup size in a geographical region will increase the likelihood that people living in that region will have (2a) friends, as well as (2b) colleagues belonging to ethnic minority groups, which in turn will reduce people's level of anti-Muslim attitudes (2c respectively $2 d$ ).

According to McLaren (2003), previous research largely neglected the distinction of several types of contact. Although Allport's (1954) 'optimal contact conditions' should be regarded mostly as facilitating, rather than necessary conditions, contact under these conditions normally will lead to even more reduction of negative attitudes towards outgroups (Pettigrew and Tropp, 2006). As mentioned previously, one of these conditions is contact that is intimate rather than casual (Amir, 1969). According to McLaren (2003), friendship is assumed to meet this condition and is therefore expected to strongly reduce negative attitudes towards ethnic minorities. This functional importance of intergroup friendship for reducing levels of outgroup derogation, was already stressed by Pettigrew (1998). Workplace contact on the other hand, may meet fewer of Allport's 'optimal contact conditions' and is therefore to be expected to less strongly reduce negative attitudes towards outgroups (Dixon and Rosenbaum, 2004). Therefore, we hypothesize that:

H3: The effect of contact on anti-Muslim attitudes will be stronger for having friends belonging to ethnic minority groups than for having colleagues belonging to ethnic minority groups.

Blalock (1967) offered an alternative hypothesis regarding the effect of outgroup size on attitudes towards outgroups, which is partly based on the mechanisms derived from both ethnic competition theory and intergroup contact theory and illustrates the complementary nature of both theories. Recently, Schneider (2008) empirically tested this so-called 'familiarization' effect of outgroup size, which boils down to the idea that a society gets used to a certain outgroup, in circumstances of high numbers. Therefore, one may assume that '[...] there is an effect of familiarization over and above individual contact' (Schneider, 2008, p. 55). The familiarization effect is based on a dynamic perspective, focusing on changes of the relative outgroup proportion. The familiarization effect assumes a curvilinear relationship between outgroup size and perceived threat, arguing that at relatively low levels of outgroup size, an increase of the outgroup size will foster levels of perceived threat (in line with ethnic competition theory), whereas further increases of the outgroup proportion will level off perceived threat. ${ }^{4}$ The latter effect is based on intergroup contact theory assuming that people get used to outgroups due to the inevitable contact with those groups in one's region. Hence, we hypothesize that:

H4: Outgroup size has a positive curvilinear effect on the level of perceived threat.

Previous studies consistently revealed identical or related individual-level determinants (referring to the conditions of actual competition) of perceived threat and negative attitudes towards different outgroups (Quillian, 1995; Scheepers et al., 2002; McLaren, 2003; Schneider, 2008). Based on these findings, we will include several individual-level determinants of perceived threat and anti-Muslim attitudes in our model: educational attainment, occupational status, income, denomination, religiosity, marital status, gender, 
and age. We will not formulate hypotheses on these effects, though only control for them in our model. Moreover, at the contextual level we will control for unemployment rates as an indicator of economic competition (cf. Scheepers et al., 2002; Coenders et al., 2008). In this way, we are able to test the effect of outgroup size on perceived threat and anti-Muslim attitudes more strictly.

Finally, we will control for the relationship between individual-level characteristics and intergroup contact. According to Schlueter and Scheepers (2010), prior studies largely neglected individual-level determinants of intergroup contact. Although some studies included individual-level determinants of intergroup contact, they used an ethnic minority perspective and/or did not address the mediating function of intergroup contact, between individual-level characteristics and negative attitudes towards outgroups (Powers and Ellison, 1995; Martinovic, Van Tubergen and Maas, 2009). Due to the absence of clear theoretical expectations on the relationship between individuallevel characteristics and intergroup contact, we decided to follow the line of Schlueter and Scheepers (2010): we did not formulate hypotheses regarding these possible effects and will only exploratorily include these relationships in our model for reasons of control in terms of overall model fit. Figure 1 shows our theoretical framework. The numbers refer to our hypotheses.

\section{Data and Measurement}

We will test our hypotheses using data derived from the Social and Cultural Developments in the Netherlands (SOCON) survey, which was conducted in the fall of 2005 up to early 2006 (Veldkamp, 2006; data available by the authors). Data were collected by face-to-face interviews with people aged 18-70 years, as well as by additional questionnaires, resulting in a final data set $(N=1,375)$, which may be assumed to be representative of the national population in the Netherlands. We only selected respondents with a Dutch nationality and whose parents and grandparents had the Dutch nationality. Moreover, we excluded respondents who considered themselves Muslim, reducing the number of individual cases to 1,214.

To construct our anti-Muslim attitudes scale, we used nine Likert items measuring people's attitudes towards Muslims living in the Netherlands, with five answer categories ranging from 'do not agree at all' to 'agree entirely': 'Muslim women who wear a scarf do not adapt to our society'; 'Muslims are dangerously fanatic'; 'Muslims use religion for political aims'; 'Muslims easily resort to violence'; 'Muslim husbands dominate their wives'; 'Muslims raise their children in an authoritarian way'; 'Muslims lock themselves out of Dutch society'; 'Muslim parents have no authority over their children outdoors'; and 'Most Muslims have no respect for homosexuals'.

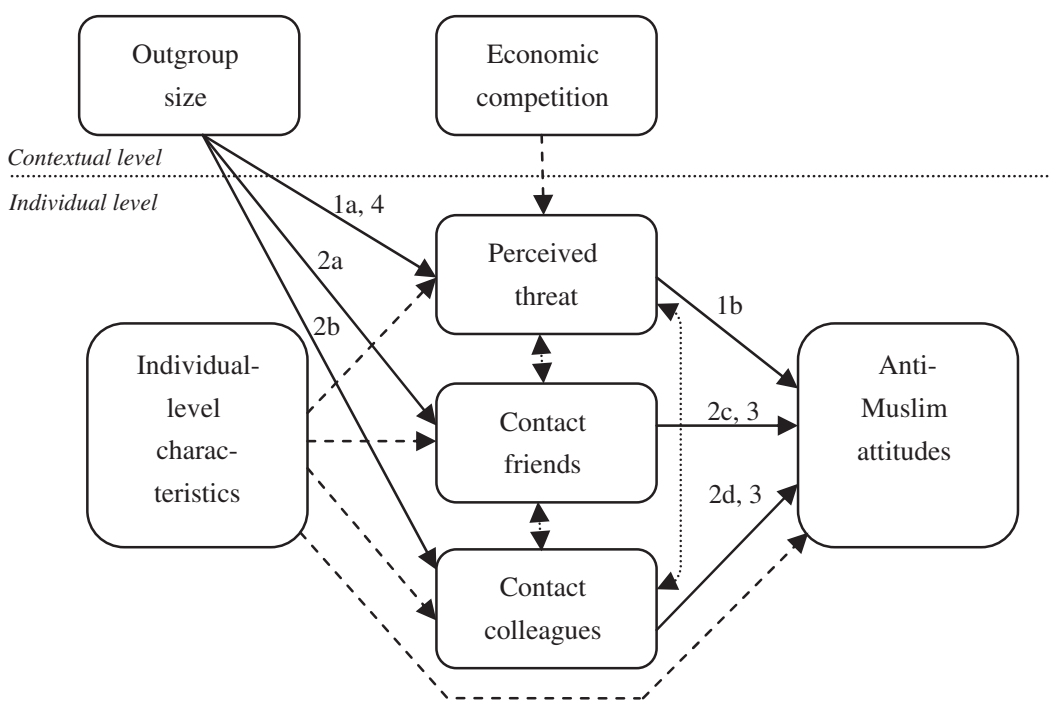

Dotted lines represent relationships which are controlled for.

Figure 1 Theoretical framework anti-Muslim attitudes 
These items were partly derived from a previous study (Sniderman et al., 2003) and some items were also used by Sniderman and Hagendoorn (2007). Using these items, we were able to construct a more detailed measurement of anti-Muslim attitudes compared with previous studies (Strabac and Listhaug, 2008). In order not to lose respondents with missing values on one or two items, we computed mean scores for respondents with valid scores at minimal six of nine items, resulting in a reliable scale (Cronbach's $\alpha=0.882$ ).

Perceived threat was measured, using four Likert items, with five answer categories ranging from 'do not agree at all' to 'agree entirely': 'Minorities get turn before Dutch people at the housing market', 'Education minorities at expense Dutch children', 'Dutch people fired because of minorities', and 'Minorities are threat to our own culture'. We performed a principal factor analysis with oblique rotation, in order to test our claim that anti-Muslim attitudes are (factorially) distinct from perceived threat (cf. Scheepers et al., 2002). The results indicated that two dimensions can be distinguished, i.e. anti-Muslim attitudes and perceived threat (see Table A1 in Appendix A). ${ }^{5}$ We constructed a scale of perceived threat, including respondents with valid scores at minimal three of four items, to prevent the loss of respondents with a missing value on one item (Cronbach's $\alpha=0.801$ ).

At the contextual level, outgroup size is measured using rather unique figures from Statistics Netherlands (2009a) on the number of Muslims as a percentage of the total population in all 40 NUTS-3 regions in the Netherlands in 2003. Dynamic data on the percentage of Muslims were, unfortunately, not available. In order to test the familiarization hypothesis, we also included the squared outgroup size in our analysis.

At the individual level, we used two measurements of contact with ethnic minorities: contact with colleagues and contact with friends. Respondents were asked about the relative part of their group of friends or colleagues who belong to an ethnic minority group. Since both measurements appeared to be relatively right skewed, we decided to construct two ordinal (i.e. ordered categorical) variables with the following categories: 'no friends'/'no colleagues' ( 0 per cent), 'few friends'/'few colleagues' ( 1 per cent $\geq$ per cent friends/colleagues $\leq 5$ per cent), 'some friends'/'some colleagues' (6 per cent $\geq$ per cent friends/colleagues $\leq 10$ per cent) and 'many friends'/'many colleagues' (per cent friends/colleagues $>10$ per cent). ${ }^{6}$ Respondents who were unemployed could still state to have colleagues belonging to ethnic minority groups (e.g. with regard to voluntary work).
We controlled for several background characteristics at the individual level, previously found to influence out-group derogation in general or ethnic threat perceptions (Scheepers, Gijsberts and Coenders, 2002; Schneider, 2008). First, we included educational attainment, which was measured in years, ranging from 6 (primary education) to 21 years (post-university education and $\mathrm{PhD}$ or doctorate). Eventually, we subtracted the minimal number of years of schooling (6), in order to obtain a meaningful zero-category. Occupational status was measured, first by asking if people were employed at the moment of data collection. Respondents who were employed, were asked about their actual occupation. We used the International Socio-Economic Index of occupational status (ISEI) scale (Ganzeboom, De Graaf and Treiman, 1992; Ganzeboom and Treiman, 1996) to distinguish three broad categories referring to relatively 'low occupational status' $(10 \leq$ ISEI-value $<35)$, 'middle occupational status' $(35 \leq$ ISEI-value $<60)$, and 'high occupational status' $(60 \leq$ ISEI-value $\leq 90)$. In this way, we were able to combine our measurement of 'occupational status' with categories referring to the 'employment situation' of respondents who were not employed. Here, we distinguished five additional categories: 'unemployed people' (i.e. people looking for paid work), 'retired people', 'students', 'homemakers', and 'else unemployed' (i.e. invalid, or performing mainly voluntary work without wage). Income was measured showing respondents a chart with two income scales, one with the household income per month and the second with the corresponding household income per year. Respondents were asked to name the letter that matched to their net household income. Since the relatively low and high income categories were rarely chosen, we condensed the answer categories into five categories: ' $<€ 1,500$ ', ' $€ 1,500-2,000$ ', '€2,000-3,000', '€3,000-4,000', and ' $>€ 4,000$ ' net per month. Furthermore, we included a sixth category 'income not reported', in order to prevent loosing respondents with a missing value on this item. In order to (indirectly) control for the household size, we also included marital status, which was measured using four categories: 'not married and never been married', 'married', 'divorced', and 'widowed'. The respondent's denomination was measured in four categories: 'Catholic', 'Protestant', 'other Christian denomination', and 'not religious' (i.e. no denomination). Religiosity was measured by the respondents' attendance of religious services, ranging from 'never/hardly ever' to 'about once a week', and included as ordinal variable. Finally, we used straightforward measures of gender and age. 
At the contextual level, we controlled for unemployment rates for each NUTS-3 region, which can be regarded as a suitable indicator of economic competition (Coenders et al., 2008). We used figures on the number of people receiving unemployment compensation in 2004, which were divided by the total labour force (people aged 15-64 years) in the same year (Statistics Netherlands, 2006).

For all variables, respondents with missing values were excluded listwise, unless described differently. This resulted in a final data set containing 1,087 respondents in 40 NUTS-3 regions. For descriptive statistics of our individual-level variables, see Table A2 (Appendix A).

\section{Analysis}

In order to test our hypotheses, we applied hierarchical structural equation modelling to estimate the proposed path model (as presented in Figure 1). In this way we are able to take the hierarchical data structure, with respondents nested in (NUTS-3) regions, into account. $^{7}$

However, using a two-level approach, our analyses did not converge. This non-convergence might be due to the complexity of our model. Previous research faced similar problems, even with much less complex models (Wagner et al., 2006). Therefore, we decided to use the Complex method in Mplus 4.0 (which takes non-independence of observations as a result of clustered data into account), fitting our models with WLSMV estimation. ${ }^{8}$ In Mplus, we constructed our path model as is depicted in Figure 1. We decided to correlate perceived threat with both types of contact. Although some previous studies considered intergroup contact to be causally antecedent to perceived threat (Schneider, 2008; Schlueter and Scheepers, 2009), the opposite causal order is not inconceivable. To our knowledge, no meta-analytical study nor empirical study using panel data have been conducted yet to disentangle this proposed causality. For reasons of control we decided to regress both measurements of contact (i.e. friends and colleagues) also on the second order term of outgroup size. This resulted in a rather good overall fit of our model, with no misspecifications being reported: RMSEA $=0.011$ (Browne and Cudeck, 1993) and $\mathrm{CFI}=0.997$ (Kline, 2005; $\mathrm{Hu}$ and Bentler, 1998).

\section{Results}

Based on both ethnic competition theory and intergroup contact theory, we expected the relationship between outgroup size and anti-Muslim attitudes to be mediated by perceptions of ethnic threat and contact with members of ethnic minority groups. Our results (Table 1) show that the outgroup size in (NUTS-3) regions in the Netherlands induces people's level of perceived threat $(b=0.098 ; \mathrm{SE}=0.039)$, which in turn appears to induce the level of anti-Muslim attitudes $(b=0.508 ; \mathrm{SE}=0.018)$. These findings corroborate hypotheses $1 \mathrm{a}$ (outgroup size inducing threat) and $1 \mathrm{~b}$ (threat inducing anti-Muslim attitudes) derived from ethnic competition theory. Note that this effect is significant after controlling for the effect of economic competition (i.e. unemployment rates) on perceived threat. If we exclude our mediating variables (i.e. perceived threat and contact) from our analysis, we also find a positive effect of outgroup size on anti-Muslim attitudes.

Next, we tested if the effect of outgroup size on anti-Muslim attitudes is also mediated by actual contact with friends and colleagues belonging to ethnic minority groups. We only found partial support for our second hypothesis. Outgroup size turned out only to positively influence the relative proportion of friends belonging to ethnic minority groups that people have $(b=0.100 ; \mathrm{SE}=0.044)$, corroborating hypothesis 2 a (outgroup size inducing contact with friends). The relative proportion of colleagues belonging to ethnic minority groups appears not to be influenced by outgroup size $(b=-0.032 ; \mathrm{SE}=0.060)$, possibly because a part of the respondents might work in a different NUTS-3 region as they live in. Only contact with colleagues turned out to reduce negative attitudes towards Muslims directly $(b=-0.043 ; \mathrm{SE}=0.016)$, which supports hypothesis $2 \mathrm{~d}$ (contact with colleagues reducing anti-Muslim attitudes). We found no direct effect of intergroup contact with friends on people's attitudes towards Muslims. Hence, we have to refute hypothesis 2c (contact with friends reducing anti-Muslim attitudes) and hypothesis 3 (relative importance intergroup friendship). These findings are in contrast with previous research (Schlueter and Wagner, 2008; Schlueter and Scheepers, 2010) showing a mediating effect of contact between outgroup size and outgroup derogation.

Although our findings indicate that the effect of outgroup size on anti-Muslim attitudes is not mediated directly by contact experiences, we found a negative correlation between both types of contact and perceived threat and a positive correlation between contact with friends and contact with colleagues. It may thus be possible, and it is indeed very likely (cf. Schlueter and Scheepers, 2010), that outgroup size 
Table 1 Results path analysis-direct effects (clustered) ( $N=1,087 ; 40$ NUTS-3 regions)

\begin{tabular}{|c|c|c|c|c|c|c|c|c|}
\hline & \multicolumn{2}{|c|}{ Perceived threat } & \multicolumn{2}{|c|}{ Contact friends } & \multicolumn{2}{|c|}{ Contact colleagues } & \multicolumn{2}{|c|}{ Anti-Muslim attitudes } \\
\hline & Estimate & SE & Estimate & SE & Estimate & SE & Estimate & SE \\
\hline Intercepts & 1.515 & 0.213 & & & & & 1.439 & 0.172 \\
\hline \multicolumn{9}{|c|}{ Independent variables (contextual level) } \\
\hline Outgroup size & 0.098 & 0.039 & 0.100 & 0.044 & -0.032 & 0.060 & 0.036 & 0.031 \\
\hline Outgroup size (squared) & -0.007 & 0.002 & -0.002 & 0.003 & 0.007 & 0.004 & -0.002 & 0.002 \\
\hline Economic competition & 0.044 & 0.050 & & & & & & \\
\hline \multicolumn{9}{|l|}{ Mediating variables } \\
\hline Contact friends & & & & & & & -0.028 & 0.019 \\
\hline Contact colleagues & & & & & & & -0.043 & 0.016 \\
\hline Perceived threat & & & & & & & 0.508 & 0.018 \\
\hline \multicolumn{9}{|c|}{ Control variables (individual level) } \\
\hline Education & -0.070 & 0.010 & 0.040 & 0.015 & 0.026 & 0.014 & -0.025 & 0.009 \\
\hline \multicolumn{9}{|c|}{ Occupational status high (ref.) } \\
\hline Occupational status middle & 0.230 & 0.074 & 0.097 & 0.097 & 0.117 & 0.128 & -0.011 & 0.060 \\
\hline Occupational status low & 0.309 & 0.080 & 0.357 & 0.195 & 0.111 & 0.162 & -0.033 & 0.063 \\
\hline Retired & 0.320 & 0.108 & 0.116 & 0.144 & -0.829 & 0.190 & -0.016 & 0.093 \\
\hline Student & 0.035 & 0.122 & 0.194 & 0.213 & -0.005 & 0.190 & -0.050 & 0.075 \\
\hline Unemployed & 0.431 & 0.149 & 0.536 & 0.284 & -0.610 & 0.298 & -0.016 & 0.099 \\
\hline Homemaker & 0.399 & 0.121 & 0.056 & 0.137 & -1.025 & 0.201 & 0.004 & 0.081 \\
\hline Else unemployed & 0.505 & 0.098 & 0.311 & 0.150 & -0.631 & 0.198 & -0.048 & 0.106 \\
\hline \multicolumn{9}{|l|}{ Income $>€ 4,000$ (ref.) } \\
\hline Income $€ 3,000-€ 4,000$ & 0.185 & 0.065 & -0.091 & 0.146 & 0.101 & 0.182 & 0.000 & 0.074 \\
\hline Income $€ 2,000-€ 3,000$ & 0.139 & 0.089 & -0.350 & 0.106 & -0.061 & 0.140 & -0.037 & 0.077 \\
\hline Income $€ 1,500-€ 2,000$ & 0.174 & 0.125 & -0.203 & 0.137 & 0.031 & 0.169 & 0.043 & 0.070 \\
\hline Income $<€ 1,500$ & 0.241 & 0.086 & -0.210 & 0.160 & -0.059 & 0.147 & -0.049 & 0.065 \\
\hline Income not reported & 0.239 & 0.115 & -0.217 & 0.123 & 0.170 & 0.110 & -0.005 & 0.100 \\
\hline Age & -0.004 & 0.003 & -0.010 & 0.004 & -0.004 & 0.004 & 0.004 & 0.001 \\
\hline \multicolumn{9}{|l|}{ Not religious (ref.) } \\
\hline Catholic & 0.181 & 0.088 & -0.321 & 0.097 & -0.002 & 0.103 & -0.022 & 0.059 \\
\hline Protestant & 0.101 & 0.075 & -0.179 & 0.152 & 0.020 & 0.121 & 0.088 & 0.068 \\
\hline $\begin{array}{l}\text { Other Christian } \\
\text { denomination }\end{array}$ & 0.238 & 0.187 & 0.622 & 0.211 & 0.635 & 0.231 & 0.060 & 0.143 \\
\hline Religiosity & -0.059 & 0.032 & -0.036 & 0.044 & -0.127 & 0.051 & -0.012 & 0.022 \\
\hline \multicolumn{9}{|l|}{ Not married (ref.) } \\
\hline Married & 0.035 & 0.093 & -0.005 & 0.091 & 0.037 & 0.109 & -0.022 & 0.043 \\
\hline Divorced & 0.018 & 0.088 & 0.165 & 0.184 & 0.208 & 0.134 & 0.066 & 0.060 \\
\hline Widowed & -0.017 & 0.117 & -0.053 & 0.184 & 0.059 & 0.210 & -0.067 & 0.100 \\
\hline Female & 0.025 & 0.046 & -0.198 & 0.078 & -0.241 & 0.083 & -0.071 & 0.039 \\
\hline$R^{2}$ & \multicolumn{2}{|c|}{0.152} & \multicolumn{2}{|c|}{0.176} & \multicolumn{2}{|c|}{0.288} & \multicolumn{2}{|c|}{0.447} \\
\hline
\end{tabular}

Source: Social and Cultural Developments in the Netherlands $(2005,2006)$.

$C F I=0.997 ; R M S E A=0.011$.

Note: Bold parameters indicate significance at $P<0.05$ (two-sided test of significance).

Empty cells: parameters not estimated due to model specifications.

Correlation Contact friends and Contact colleagues: 0.346 (SE 0.037); Correlation Perceived threat and Contact friends: -0.106 (SE 0.024); Correlation Perceived threat and Contact colleagues: -0.059 (SE 0.028).

Residual variances: Anti-Muslim attitudes: 0.296 (SE 0.011); Perceived threat: 0.621 (SE 0.028).

increases the likelihood of having contact with friends, which in turn reduces ethnic threat perceptions and eventually anti-Muslim attitudes. Sensitivity analyses, using single item measures of perceived threat, show substantially similar results as presented in Table 1 (available on request). ${ }^{9}$ We will come back to this in the conclusion.
Based on the familiarization hypothesis, we expected that the positive effect of the outgroup size on perceived threat is curvilinear rather than linear. Here, a mechanism of 'unavoidable contact' over and above direct contact with friends and colleagues is supposed to reduce levels of perceived ethnic threat if the relative proportion of Muslims in a 
region increases. As one can see in Table 1, both the positive first order term $(b=0.098 ; \mathrm{SE}=0.039)$, as well as the negative quadratic term $(b=-0.007$; $\mathrm{SE}=0.002)$ are significant, indicating that the (initial) positive slope of percentage Muslims levels off and decreases with increasing percentages Muslims in (NUTS-3) regions (turning point at 7.00 per cent Muslims in a NUTS-3 region). This corroborates hypothesis 4 (familiarization). Note that if we exclude our mediating variables (i.e. perceived ethnic threat and contact) from our analysis, we find a curvilinear effect of outgroup size on anti-Muslim attitudes (first order term: $b=0.085 ; \mathrm{SE}=0.038$; second order term: $b=-0.006 ; \mathrm{SE}=0.002$ ).

The curvilinear effect of the percentage of Muslims on perceived threat is presented in Figure 2. As one can see this effect is (mainly) influenced by the four (NUTS-3) regions with the highest percentages of Muslims: 'Groot-Amsterdam' (12.7 per cent), 'Agglomeration The Hague' (11.0 per cent), 'Groot-Rijnmond' (including Rotterdam) (9.9 per cent) and 'Zaanstreek' (8.8 per cent). Three of these regions comprise the largest cities of the Netherlands. This is rather obvious as one may expect the familiarization effect to take place in these regions in particular. $^{10}$

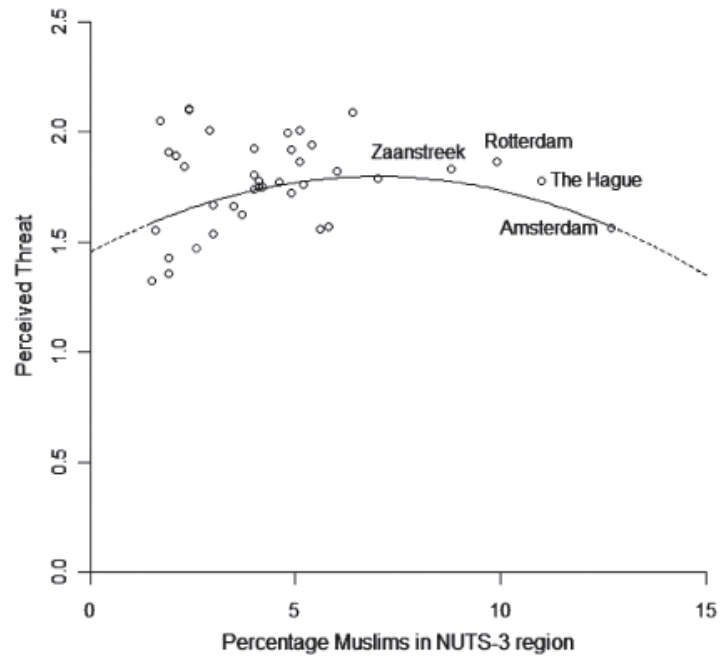

Dots represent NUTS- 3 regions (mean perceived ethnic threat by percentage Muslims); Curve $(\mathrm{Y}=1.454+0.098 \times$ Percentage Muslims $-0.007 \times$ Percentage Muslims squared) is based on estimates Table 1, intercept refers to mean score perceived threat controlled for percentage Muslims; Dashed line based on extrapolation.

Figure 2 Curvilinear effect percentage Muslims in NUTS-3 regions on perceived threat
Based on our findings, we conclude that perceived ethnic threat plays an important mediating role with regard to the effect of outgroup size on anti-Muslim attitudes. The mediating function of intergroup contact in this respect is less clear. Although the causal order between intergroup contact and perceived threat is left an open question, our results revealed a negative correlation between both types of contact and perceptions of threat.

Finally, we want to call attention to the mediating role of contact and threat between, on the one hand, the individual-level characteristics and, on the other hand, anti-Muslim attitudes (Table A3 in Appendix A). Our results are in line with previous studies on individual-level determinants (referring to conditions of actual competition) of perceived threat and negative attitudes towards different outgroups (Scheepers et al., 2002; Schneider, 2008). In particular lower educational attainment and lower occupational status (including categories referring to being unemployed) turn out to increase people's level of perceived threat, which in turn induces people's level of anti-Muslim attitudes. Regarding income and religious denomination, only some categories appear to have an effect on anti-Muslim attitudes via perceived threat.

With regard to the mediating role of intergroup contact, prior studies mainly focused on the effect of contact on outgroup derogation, thereby largely neglecting individual-level determinants of intergroup contact (Schlueter and Scheepers, 2010). Our results revealed that contact with colleagues mediates the effect of several individual-level characteristics (e.g. gender, religiosity, and several categories of occupational status) on anti-Muslim attitudes. The effect of occupational status on attitudes towards Muslims is jointly mediated with ethnic threat perceptions. Although contact with friends belonging to ethnic minority groups turns out not to directly affect anti-Muslim attitudes, our results provide insights into the underlying determinants of this kind of contact. As one can see in Table 1, contact with friends belonging to ethnic minority groups turns out to be influenced by several individual-level determinants as well (e.g. educational attainment, age, and gender). This is in line with the findings of Schlueter and Scheepers (2010), showing that younger people as well as higher educated people have more intergroup contact. However, Schlueter and Scheepers used a combined measurement of contact with both friends and colleagues. Using two separate measurements of contact, our results illustrate that different determinants appear to affect different types of contact. An overview of our results is presented in Figure 3. 


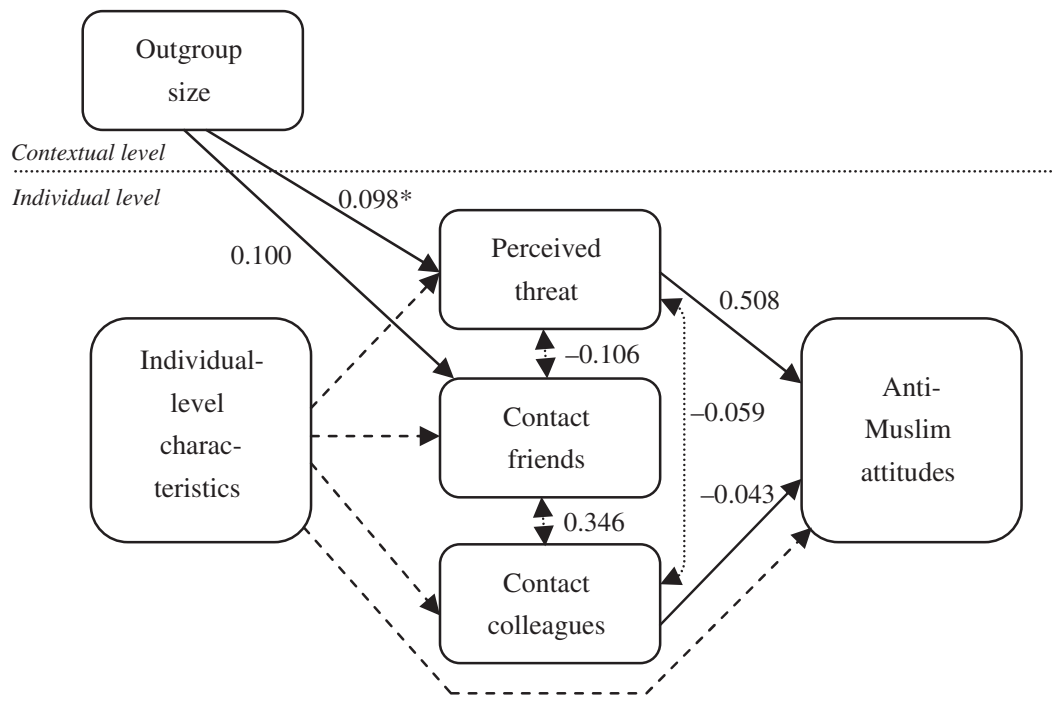

Only significant effects presented.

Asterisks indicate curvilinear effect of outgroup size on perceived threat (coefficient first order term: 0.098; coefficient second order term: -0.007 ).

Dotted lines represent effects from individual-level characteristics on the mediating variables and anti-Muslim attitudes which are controlled for.

Figure 3 Results path analysis

\section{Conclusions and Discussion}

In this study, we set out to explain negative attitudes towards Muslims in the Netherlands, which has been largely neglected in previous research. As similar mechanisms underlying unfavourable attitudes towards ethnic minorities in general are supposed to influence anti-Muslim attitudes as well (Strabac and Listhaug, 2008), we applied two general theories, from which we derived contradictory expectations: ethnic competition theory and intergroup contact theory. We focused on the influence of the relative size of the Muslim population in (NUTS-3) regions on anti-Muslim attitudes. This is an interesting relationship as both theories propose diverse mechanisms underlying this relationship and eventually lead to contradictory hypotheses. Ethnic competition theory proposes that a larger outgroup size fosters people's level of perceived threat, which in turn will induce their level of anti-Muslim attitudes. On the other hand, intergroup contact theory states that a larger outgroup size will induce the likelihood that people will have contact with friends and colleagues belonging to ethnic minority groups, which in turn will reduce anti-Muslim attitudes.
The results of our hierarchical path model corroborate hypothesis 1: outgroup size appeared to induce perceived threat (even if we control for unemployment rates at the contextual level), which in turn induces anti-Muslim attitudes. Moreover, we found support for hypothesis 4 (familiarization), which illustrates the complementary nature of ethnic competition theory and intergroup contact theory and proposes that people living in regions with high numbers of outgroups get used to and are more experienced with integration of a certain outgroup (Blalock, 1967; Schneider, 2008). This effect assumes a process in time taking place (i.e. a dynamic perspective), inducing unavoidable contact with outgroups at the individual level, due to proximity. Eventually, this process will reduce people's level of perceived ethnic threat. Our results showed a curvilinear effect of outgroup size on perceived threat: the initial positive effect of outgroup size on perceived threat levels off and decreases at larger outgroup proportions. Perceived threat, in turn, appeared (as we expected) to induce people's level of anti-Muslim attitudes. Interestingly, this curvilinear effect (i.e. the change of the direction of the slope) appears to be (mainly) influenced by four (NUTS-3) regions with the largest Muslim populations (three of 
which comprise the largest cities in the Netherlands). As non-Western immigrants in general traditionally live in the (four) largest cities of the Netherlands (Wittebrood, Latten and Nicolaas, 2005), these findings support our expectations that the majority population has been able to get used to the presence of Muslims during a certain period of time and as a result perceives less threat due to their presence.

Next to the 'familiarization' hypothesis, which assumes a mechanism of 'unavoidable' contact taking place, we expected direct contact with people belonging to ethnic minority groups to influence anti-Muslim attitudes as well. Based on intergroup contact theory, we supposed a larger outgroup size to increase the likelihood that people will have contact with friends and colleagues belonging to ethnic minority groups, which in turn will reduce levels of anti-Muslim attitudes. We only found a positive direct effect of outgroup size on intergroup friendship, whereas only intergroup contact with colleagues turned out to reduce anti-Muslim attitudes directly. This is only partially in line with our expectations as well as previous findings. Note, however, that in contrast with previous studies (Schlueter and Wagner, 2008; Schlueter and Scheepers, 2010), we used two separate measurements of contact: contact with friends and contact with colleagues belonging to ethnic minority groups, which might partly explain our results. One has to keep in mind, however, that the distinction between both types of intergroup contact is not only interesting from a theoretical point of view (as contact with friends meets relatively more optimal contact conditions than contact with colleagues does; see Allport, 1954; Pettigrew and Tropp, 2006), it has another advantage as well. Since contact with colleagues is less voluntarily in nature and therefore less likely to be affected by selectivity compared with intergroup friendship, we were able to (partly) get around the issue of causality of contact.

Although the distinction between both types of contact might partly explain our results regarding the mediating effect of intergroup contact, we are aware of the possibility that our measurement of contact might have influenced our findings as well. As mentioned previously, due to data limitations, we had to use two measurements of contact referring to ethnic minorities in general, rather than Muslims in particular. This might have resulted in a slight underestimation of the effects of intergroup contact. However, one should bear in mind that in the Netherlands a rather large proportion of the ethnic minority population is Muslim (Statistics Netherlands, 2008). Moreover, both contact variables could only be measured with one item, whereas perceived threat is measured more reliably using four items. As a result, the co-variation of contact with outgroup size as well as anti-Muslim attitudes might be relatively underassessed. Hence, we conducted several sensitivity analyses, using single-item measurements of perceived threat. The results of these additional analyses turned out to be substantially similar with our original findings: we always found a direct effect of perceived threat and intergroup contact with colleagues on anti-Muslim attitudes. Based on our general findings, as well as the results of our sensitivity analyses, we conclude that the mediating effect of intergroup contact is rather complex. As argued before, it is likely that intergroup contact reduces perceptions of ethnic threat and eventually anti-Muslim attitudes (cf. Schlueter and Scheepers, 2010). The causal order between both mediating variables remains, however, unclear, as previous research lacks an adequate test of the causality between contact and perceived threat and our cross-sectional data did not allow us to unambiguously test this causal order.

The issue of causality related to intergroup contact theory is not new. Pettigrew (1998) already pointed to solutions to deal with the issue of selectivity regarding intergroup contact and outgroup derogation. $\mathrm{He}$ suggested, for instance, the selection of contact situations with limited opportunities to choose for participation (which we have done in terms of contact with colleagues) and the use of panel data to overcome this problem. Both strategies can also be applied to cope with the issue of causality between intergroup contact and perceived threat. We would like, however, to put forward another strategy to deal with this issue, which also addresses a second underlying aspect: not only will people with more positive attitudes be less likely to avoid intergroup contact, those who have intergroup contact will have probably contact with relatively liberal and well integrated outgroup members, who do not avoid contact either. By conducting an experimental design, future research could disentangle the effect of contact with random outgroup members on random respondents' attitudes towards outgroups.

Summarizing, applying general theories to explain attitudes towards Muslims, our results turned out to be largely in line with previous studies on outgroup derogation in general. Although these theories are basically 'colour blind', both perceptions of ethnic threat as well as intergroup contact appeared to be important explanatory mechanisms for the effect of outgroup size on anti-Muslim attitudes. Moreover, our findings show that perceptions of ethnic threat mediate the effects of several individual-level characteristics 
(e.g. educational attainment and occupational status) on anti-Muslim attitudes, just like previously found in studies on resistance to minorities more in general. Our results provide some rather unique and interesting findings on the intervening role contact plays between on the one hand individual-level characteristics and on the other hand anti-Muslim attitudes. Several effects of individual-level determinants on anti-Muslim attitudes (e.g. gender and religiosity) appear to be mediated by contact. These findings are partially in line with previous exploratory research on this aspect (Schlueter and Scheepers, 2010) and illustrate the importance for future research to address the individual-level sources of intergroup contact. Finally, our findings illustrate the complementary nature of both ethnic competition theory and intergroup contact theory. This becomes not only clear from the corroboration of the familiarization hypothesis, though is also underlined by the fact that both mediating mechanisms turned out to be negatively interrelated. Policymakers should therefore focus at intergroup contact stimulating measures, as contact not only reduces outgroup derogation in general (as has been showed by previous research time and again), though also appears to reduce perceived ethnic threat, which in turn is an important determinant of anti-Muslim attitudes. However, as both mediating mechanisms turned out to be rather complex, they deserve more attention in future research.

\section{Notes}

1. Estimates range from 7 to 15 million Muslims living in Europe (Zolberg and Woon, 1999; Fetzer and Soper, 2003; Modood, 2003).

2. We will use the NUTS-3 level (Nomenclature of Statistical Territorial Units) as our contextual level. With an average population size ranging from 150,000 to 800,000 , the NUTS-3 level is positioned between the municipality and province level (Eurostat, 2008). This level is useful for cross-cultural comparisons since it is standardized with regard to population size (which is not the case with for instance the neighbourhood level).

3. As our data do not contain measurements of contact with Muslims in particular, we will have to use two measurements of contact with ethnic minorities in general (i.e. contact with friends and colleagues). Since, however, the non-Western immigrant population in the Netherlands consists to a relatively large extent of Muslims (Statistics Netherlands, 2008), we suppose the use of these measurements to be justifiable. Moreover, we are aware of the fact that people may work in a different NUTS-3 region from where they live (in general this is the case for 29 per cent of the people with a paid job in the Netherlands; see Statistics Netherlands, 2009b). For the respondents in our dataset we have, however, no information regarding the NUTS-3 region they work in.

4. Schneider (2008) implicitly assumes a process in time taking place. People living in geographical regions with a large outgroup proportion, were able to get used to the presence of the outgroup over a certain period of time, since one may suppose the arrival and settlement of large outgroup proportions to take several years or even decades. However, Schneider (2008) did not take this process into consideration. She assumed countries with large outgroup proportions at a certain moment already to have gone through this process of familiarization. Since our present study is cross-sectional and we have no dynamic data available on the relative outgroup size in regions, we will follow the line of Schneider (2008).

5. If we compare a one-factor solution $\left(\chi^{2}=469.208\right.$; $\mathrm{df}=65 ; \mathrm{RMSEA}=0.086$; CFI $=0.912)$ with a twofactor solution $\quad\left(\chi^{2}=221.992 ; \quad \mathrm{df}=64\right.$; RMSEA $=0.054 ; \mathrm{CFI}=0.966)$, the latter fits the data significantly better $(P<0.005)$.

6. By including both measurements of contact on an ordinal scale, we are able to treat them as endogenous variables in our analysis, since nominal variables cannot be used as mediating variables conducting a path analysis with Mplus 4.0. In order not to lose respondents with missing values, we tested if respondents who did not provide any information, differed from respondents who stated that they did not have any colleagues or friends belonging to ethnic minorities. Regressing our dependent variable (antiMuslim attitudes) on dummy categories of both types of contact, our results revealed that in both cases the missing category does not differ significantly from our reference categories ('no colleagues', respectively 'no friends'). Finally, we tested if a nominal variable (with a dummy 
variable for each category) would result in a higher level of explained variance $\left(R^{2}\right)$ of our dependent variable, compared with the (semi-) interval variable. The results (for both contact with friends as well as contact with colleagues) indicate that the increase of $R^{2}$ of the dependent variable, when using the nominal variable, is significant $(P<0.050)$, however, rather small $\left(\Delta R^{2}=0.007\right)$. Since we cannot conduct a path analysis in Mplus, using a nominal variable as mediating variable, and the increase of the $R^{2}$ of the dependent variable is rather small when using a nominal variable, we decided to include both types of contact as ordinal variables in our analysis.

7. Although the intraclass correlation coefficient for our dependent variable (i.e. anti-Muslim attitudes) appeared to be rather low $(\rho=0.017)$, the model fit $(-2 \log$ likelihood $=2,401.267)$ for a null model with a random intercept for our dependent variable appeared to be better, compared with the model fit for a null model with a fixed intercept $(-2 \log$ likelihood $=2,407.922)$. This difference in model fit is significant $\left(\Delta \chi^{2}=6.655\right.$; with $\mathrm{df}=1$; significant at $P<0.010)$, indicating that the hierarchical structure in the data has to be taken into account.

8. As the intraclass correlation coefficient of our dependent variable is rather low $(P=0.017)$, we assume this analysis to be justifiable (Muthén and Satorra, 2005). Furthermore, previous research (Wagner et al., 2006) applied this strategy also to solve problems of non-convergence of analyses of (complex) hierarchical data structures. Due to the ordinal measurement of our mediating variables of contact with friends and colleagues, we had to use WLSMV estimation instead of maximum likelihood estimation. For more information on WLSMV estimation, see Muthén and Muthén (1998-2007).

9. As we are aware of the risk of underassessing the co-variation of contact with outgroup size and antiMuslim attitudes, due to a less reliable measurement of intergroup contact (both types of contact measured with one item), compared with our measurement of perceived threat (measured with four items), we decided to estimate our model with a single-item measurement of perceived threat, successively using our four threat items The results of these sensitivity analyses were substantially similar with our original findings: we always found a direct effect of perceived threat and intergroup contact with colleagues on anti-Muslim attitudes. We found one minor exception as both items referring to cultural threat (v2152) and 'immaterial' threat (v0640) seem to explain the effect of intergroup friendship on anti-Muslim attitudes.

10. We conducted several tests in order to detect influential cases on the contextual level. Diagnostics on influential cases (Mahalanobis and Cook's Distance statistics) indicated that several NUTS-3 regions might be influential cases and therefore should be excluded from the analysis. We tested our model several times, leaving different NUTS-3 regions out of the analysis. Our estimates for both the effect of outgroup size and outgroup size squared on perceived threat, only differed slightly. For all regions except one, the estimates were still significant at $P<0.05$ (two-sided test of significance). If NUTS-3 region 'Groot-Amsterdam' was excluded, the curvilinear effect of outgroup size (i.e. both the first and second order term) is significant at $P<0.10$ (two-sided test of significance). However, the positive effect of outgroup size on contact with friends belonging to ethnic minority groups was no longer significant. Hence, one may consider NUTS-3 region 'GrootAmsterdam' to be an influential case. One has, however, to keep in mind that this region has the largest percentage of Muslims in the Netherlands (12.7 per cent) and is one of the largest regions in terms of number of respondents (86 respondents; 7.912 per cent). We decided to include all 40 NUTS-3 regions in our analysis, though want to emphasize that some effects have to be considered carefully.

\section{Acknowledgements}

The authors would like to thank the ESR's anonymous reviewers for their constructive comments.

\section{References}

Allen, C. and Nielsen, J. S. (2002). Summary report on Islamophobia in the E.U. after 11 September 2001. 
Vienna: European Monitoring Centre on Racism and Xenophobia.

Allport, G. W. (1954/1979). The Nature of Prejudice. Boston: Beacon Press.

Amir, Y. (1969). Contact hypothesis in ethnic relations. Psychological Bulletin, 71, 319-342.

Amir, Y. (1976). The role of intergroup contact in change in prejudice and race relations. In Katz, P. and Taylor, D. A. (Eds.), Towards the Elimination of Racism. New York: Pergamon Press, pp. 245-308.

Amir, Y. and Ben-Ari, R. (1986). International tourism, ethnic contact, and attitude change. Journal of Social Issues, 41, 105-115.

Austin, W. G. and Worchel, S. (1979). The Social Psychology of Intergroup Relations. Monterey, California: Brooks/Cole.

Billiet, J., Eisinga, R. and Scheepers, P. (1996). Ethnocentrism in the low countries: a comparative perspective. New Community, 22, 401-416.

Blalock, H. M. (1967). Toward a Theory of Minority Group Relations. New York: John Wiley and Sons.

Bobo, L. D. (1988). Group conflict, prejudice, and the paradox of contemporary racial attitudes. In Katz, P. A. and Taylor, D. A. (Eds.), Eliminating Racism. Profiles in Controversy. New York: Plenum Press, pp. 85-114.

Brown, R. (1995). Prejudice. Its Social Psychology. Oxford: Blackwell.

Brown, R. (2000). Social identity theory: past achievements, current problems and future challenges. European Journal of Social Psychology, 30, 745-778.

Browne, M. W. and Cudeck, R. (1993). Alternative ways of assessing model fit. In Bollen, K. A. and Long, J. S. (Eds.), Testing Structural Equation Models. Newbury Park, CA: Sage, pp. 136-162.

Coenders, M., Gijsberts, M., Hagendoorn, L. and Scheepers, P. (2004). Introduction. In Gijsberts, L., Hagendoorn, L. and Scheepers, P. (Eds.), Nationalism and Exclusion of Migrants: Cross-National Comparisons. Altershot: Ashgate, pp. 1-25.

Coenders, M., Lubbers, M., Scheepers, P. and Verkuyten, M. (2008). More than two decades of changing ethnic attitudes in the Netherlands. Journal of Social Issues, 64, 269-285.

Coser, L. A. (1956). The Function of Social Conflict. Glencoe, Illinois: Free Press.

Dixon, J. C. and Rosenbaum, M. S. (2004). Nice to know you? Testing contact, cultural and group threat theories of anti-Black and antiHispanic stereotypes. Social Science Quarterly, 85, 257-280.
ECRI (2008). Derde rapport over Nederland [Third report on the Netherlands]. Strassbourg: European Commission against Racism and Intolerance.

Eurostat (2008). Introduction to the NUTS and the Statistical Regions of Europe. Available from: $<$ http://ec.europa.eu/eurostat $>$ [accessed November 2008].

Fetzer, J. S. and Soper, J. C. (2003). The roots of public attitudes toward state accommodation of European Muslims' religious practices before and after September 11. Journal for the Scientific Study of Religion, 42, 247-258.

Ganzeboom, H. B. G., De Graaf, P. M. and Treiman, D. J. (1992). A standard international socio-economic index of occupational status. Social Science Research, 21, 1-56.

Ganzeboom, H. B. G. and Treiman, D. J. (1996). Internationally comparable measures of occupational status for the 1988 international standard classification of occupations. Social Science Research, 25, 201-239.

González, K. V., Verkuyten, M., Weesie, J. and Poppe, E. (2008). Prejudice toward Muslims in the Netherlands: testing integrated threat theory. British Journal of Social Psychology, 47, 667-685.

$\mathrm{Hu}$, L. and Bentler, P. M. (1998). Fit indices in covariance structure modelling: sensitivity to underparameterized model specifications. Psychological Methods, 3, 424-453.

Kline, R. B. (2005). Principles and Practice of Structural Equation Modeling, 2nd edn. New York/London: The Guilford Press.

LeVine, R. A. and Campbell, D. T. (1972). Ethnocentrism: Theories of Conflict, Ethnic Attitudes, and Group Behaviour. New York: John Wiley and Sons.

Martinovic, B., Van Tubergen, F. and Maas, I. (2009). Dynamics of interethnic contact: a panel study of immigrants in the Netherlands. European Sociological Review, 25, 303-318.

McLaren, L. M. (2003). Anti-immigrant prejudice in Europe: contact, threat perception, and preferences for the exclusion of migrants. Social Forces, 81, 909-936.

Mclaren, L. and Johnson, M. (2007). Resources, group conflict and symbols: explaining anti-immigration hostility in Britain. Political Studies, 55, 709-732.

Modood, T. (2003). Muslims and the politics of difference. The Political Quarterly, 74, 100-115.

Muthén, L. K. and Muthén, B. O. (1998-2007). Mplus User's Guide, 5th edn. Los Angeles, CA: Muthén \& Muthén. 
Muthén, B. O. and Satorra, A. (1995). Complex sample data in structural equation modeling. Sociological Methodology, 25, 267-316.

Olzak, S. (1992). The Dynamics of Ethnic Competition and Conflict. Standford, CA: Stanford University Press.

Pettigrew, T. F. (1998). Intergroup contact theory. Annual Review of Psychology, 49, 65-85.

Pettigrew, T. F. and Tropp, L. R. (2006). A metaanalytic test of intergroup contact theory. Journal of Personality and Social Psychology, 90, 751-783.

Powers, D. A. and Ellison, C. G. (1995). Interracial contact and black racial attitudes: the contact hypothesis and selectivity bias. Social Forces, 74, 205-226.

Quillian, L. (1995). Prejudice as a response to perceived group threat: population composition and anti-immigrant and racial prejudice in Europe. American Sociological Review, 60, 586-611.

Sander, A. (2005). Experiences of Swedish Muslims after the terror attacks in the USA on 11 September 2001. Journal of Ethnic and Migration Studies, 32, 809-830.

Scheepers, P., Gijsberts, M. and Coenders, M. (2002). Ethnic exclusionism in European countries. Public opposition to civil rights for legal migrants as a response to perceived ethnic threat. European Sociological Review, 18, 17-34.

Schlueter, E., Schmidt, P. and Wagner, U. (2008). Disentangling the causal relations of perceived group threat and outgroup derogation: cross-national evidence from German and Russian panel surveys. European Sociological Review, 24, 567-581.

Schlueter, E. and Scheepers, P. (2010). The relationship between outgroup size and anti-outgroup attitudes: A theoretical synthesis and empirical test of group threat- and intergroup contact theory. Social Science Research, 39, 285-295.

Schlueter, E. and Wagner, U. (2008). Regional differences matter. Examining the dual influence of the regional size of the immigrant population on derogation of immigrants in Europe. International Journal of Comparative Sociology, 49, 153-173.

Schneider, S. L. (2008). Anti-immigrant attitudes in Europe: outgroup size and perceived ethnic threat. European Sociological Review, 24, 53-67.

Sniderman, P. M., Hagendoorn, L. and Prior, M. (2003). De moeizame acceptatie van moslims in Nederland [The difficult acceptance of Muslims in the Netherlands]. Mens \& Maatschappij, 78, 199-217.

Sniderman, P. M., Hagendoorn, L. and Prior, M. (2004). Predisposing factors and situational triggers: exclusionary reactions to immigrant minorities. American Political Science Review, 98, 35-49.
Sniderman, P. M. and Hagendoorn, L. (2007). When Ways of Life Collide. Princeton, New Jersey: Princeton University Press.

Statistics Netherlands (2006). Kerncijfers wijken en buurten 2003-2006 [Core Figures Districts and Quarters]. Dataset, The Hague/Heerlen: CBS. Statistics Netherlands, figures, Statline database. Available from: <http://www.cbs.nl> [accessed November 2008].

Statistics Netherlands (2008). Population; Muslims and Hindus in the Netherlands. Statistics Netherlands, figures, Statline database. Available from: <http:// www.cbs.nl> [accessed November 2008].

Statistics Netherlands (2009a). Religie naar region 2000/ 2002 of 2003 [Religion by Area 2000/2002 or 2003]. Statistics Netherlands, figures, Statline database. Available from: <http://www.cbs.nl> [accessed February 2009].

Statistics Netherlands (2009b). Woon- en werk regio Hoofdbanen, 2005 [Living and Working region Main Jobs, 2005]. Statistics Netherlands, figures, Statline database. Available from: <http://www.cbs.nl> [accessed November 2009].

Strabac, Z. and Listhaug, O. (2008). Anti-Muslim prejudice in Europe: a multilevel analysis of survey data from 30 countries. Social Science Research, 37, 268-286.

Tajfel, H. (1981). Human Groups and Social Categories. Studies in Social Psychology. Cambridge: Cambridge University Press.

Tajfel, H. (1982). Social psychology of intergroup relations. Annual Review of Psychology, 33, 1-39.

Tajfel, H. and Turner, J. (1979). An integrative theory of intergroup conflict. In Austin, W. G. and Worchel, S. (Eds.), The Social Psychology of Intergroup Relations. Monterey, California: Brooks/Cole, pp. 33-47.

Taylor, M. C. (1998). How white attitudes vary with the racial composition of local populations: numbers count. American Sociological Review, 63, 512-535.

Tolsma, J., Lubbers, M. and Coenders, M. (2008). Ethnic competition and opposition to ethnic intermarriage in the Netherlands: a multi-level approach. European Sociological Review, 24, 215-230.

Tolsma, J., Van der Meer, T. and Gesthuizen, M. (2009). The impact of neighbourhood and municipality characteristics on social cohesion in the Netherlands. Acta Politica, 44, 286-313.

Turner, J. C. (1982). Towards a cognitive redefinition of the social group. In Tajfel, H. (Ed.), Social Identity and Intergroup Relations. Cambridge: Cambridge University Press, pp. 15-40.

Veldkamp, (2006). Veldwerkverslag 'Sociaal Culturele Ontwikkelingen in Nederland 2005' [Fieldwork 
report 'Social and cultural developments in the Netherlands 2005'] (SOCON 2005, 2006). Amsterdam: Veldkamp.

Wagner, U., Christ, O., Pettigrew, T. F., Stellmacher, J. et al. (2006). Prejudice and minority proportion: Contact instead of threat effects. Social Psychology Quarterly, 69, 380-390.

Wittebrood, K., Latten, J. and Nicolaas, H. (2005). Wonen, leefbaarheid en veiligheid in concentratiewijken [Living, liveability and safety in 'concentrated' neighbourhoods]. In Jaarrapport Integratie 2005 [Year report on integration 2005]. The Hague: SCP/WODC/CBS.

Zolberg, A. R. and Woon, L. L. (1999). Why Islam is like Spanish: cultural incorporation in Europe and the United States. Politics and Society, 27, 5-38.
University Nijmegen, PO Box 9104, 6500 HE, Nijmegen, the Netherlands.

Email: m.savelkoul@maw.ru.nl.

Peer Scheepers, Department of Social Science Research Methodology, Radboud University Nijmegen, PO Box 9104, 6500 HE, Nijmegen, the Netherlands.

Email: p.scheepers@maw.ru.nl.

Jochem Tolsma, Department of Sociology, Radboud University Nijmegen, PO Box 9104, 6500 HE, Nijmegen, the Netherlands.

Email: j.tolsma@maw.ru.nl.

Louk Hagendoorn, Department of General Social Sciences, Utrecht University, PO Box 80140, 3508 TC Utrecht, The Netherlands.

Email: 1.hagendoorn@fss.uu.nl.

Manuscript received: November 2009

Michael Savelkoul (to whom correspondence should be addressed), Department of Sociology, Radboud

\section{Appendix A}

Table A1 Factor loadings anti-Muslim attitudes and perceived threat (Oblique rotation) $(N=1,214)$

Item

$\begin{array}{ll}\text { Anti-Muslim } & \text { Perceived } \\ \text { attitudes } & \text { threat }\end{array}$

V2135 Muslim women who wear a scarf do not adapt to our society

0.417

0.273

V2136

V2139

V2140

V5104

V5105

V5106

V5107

V5108

V0639

V0640

V0642

V2152
Muslims are dangerously fanatic

Muslims use religion for political aims

Muslims easily resort to violence

Muslim husbands dominate their wives

Muslims raise their children in authoritarian way

Muslims lock themselves out of Dutch society

Muslim parents have no authority over their children outdoors

Most Muslims have no respect for homosexuals

Minorities get turn before Dutch people at the housing market

Education minorities at expense Dutch children

Dutch people fired because of minorities

Minorities are threat to our own culture
0.522

0.701

0.635

0.780

0.595

0.664

0.540

0.698

$-0.014$

0.057

$-0.034$

0.248
0.319

0.073

0.179

$-0.121$

$-0.049$

0.121

0.123

$-0.083$

0.708

0.694

0.734

0.562

Source: Social and Cultural Developments in the Netherlands (2005, 2006). 
Table A2 Descriptive statistics individual level $\operatorname{SOCON}(2005,2006)(N=1,087)$

Variable

Mean/

Percentage

Anti-Muslim attitudes (0-4)

Perceived threat $(0-4)$

Contact friends belonging to ethnic minorities (0-3)

Contact colleagues belonging to ethnic minorities $(0-3)$

Educational attainment (years) $(6=0),(0-15)$

Age $(18=0),(0-52)$

Religiosity (0-3)

Occupational status (\%)

Occupational status high (ref.)

Occupational status middle

Occupational status low

Retired people

Students

Unemployed people

Homemakers

Else unemployed

Income per month (\%)

$>€ 4,000$ (ref.)

$€ 3,000-4,000$

$€ 2,000-3,000$

$€ 1,500-2,000$

$<€ 1,500$

Income not reported

Religious denomination (\%)

Not religious (ref.)

Catholic

Protestant

Other Christian denomination

Marital status (\%)

Not married/never been married (ref.)

Married

Divorced

Widowed

Gender (\%)

Male (ref.)

Female

18

32

12

15

4

2

10

7

12

16

26

13

20

13

61

19

17

3

28

56

10

6

48

52
Std. dev.

0.733

0.856

1.090

1.162

2.949

14.618

1.024

$\begin{array}{rr}2.379 & 0.733 \\ 1.785 & 0.856 \\ 0.841 & 1.090 \\ 0.897 & 1.162 \\ 6.134 & 2.949 \\ 28.384 & 14.618 \\ 0.736 & 1.024\end{array}$

Source: Social and Cultural Developments in the Netherlands $(2005,2006)$. 
Table A3 Results path analysis—direct and indirect (significant) effects (clustered) $(N=1,087 ; 40$ NUTS-3 regions)

\section{Direct effect on anti-Muslim attitudes}

\section{Indirect effects via contact via collective colleagues threat}

Total effect on anti-Muslim attitudes

\begin{tabular}{|c|c|c|c|c|}
\hline \multicolumn{5}{|l|}{ Independent variables (contextual level) } \\
\hline Outgroup size & & & 0.050 & 0.050 \\
\hline Outgroup size (squared) & & & -0.004 & -0.004 \\
\hline \multicolumn{5}{|l|}{ Control variables (individual level) } \\
\hline Education & -0.025 & & -0.036 & -0.061 \\
\hline \multicolumn{5}{|l|}{ Occupational status high (ref.) } \\
\hline Occupational status middle & & & 0.117 & 0.117 \\
\hline Occupational status low & & & 0.157 & 0.157 \\
\hline Retired & & 0.036 & 0.163 & 0.199 \\
\hline Unemployed & & 0.026 & 0.219 & 0.245 \\
\hline Homemaker & & 0.044 & 0.203 & 0.247 \\
\hline Else unemployed & & 0.027 & 0.257 & 0.284 \\
\hline \multicolumn{5}{|l|}{ Income $>€ 4,000$ (ref.) } \\
\hline Income $€ 3,000-€ 4,000$ & & & 0.094 & 0.094 \\
\hline Income $<€ 1,500$ & & & 0.122 & 0.122 \\
\hline Income not reported & & & 0.121 & 0.121 \\
\hline Age & 0.004 & & & 0.004 \\
\hline \multicolumn{5}{|l|}{ Not religious (ref.) } \\
\hline Catholic & & & 0.092 & 0.092 \\
\hline Other christian denomination & & -0.027 & & -0.027 \\
\hline Religiosity & & 0.005 & & 0.005 \\
\hline Female & & 0.010 & & 0.010 \\
\hline
\end{tabular}

Source: Social and Cultural Developments in the Netherlands (2005, 2006).

Note: only significant effects $(P<0.05$; two-sided test of significance).

Correlation Contact friends and Contact colleagues: 0.346 (SE 0.037); Correlation Perceived threat and Contact friends: -0.106 (SE 0.024); Correlation Perceived threat and Contact colleagues -0.059 (SE 0.028). 